\title{
Probing Topological Electronic Effects in Catalysis: Thiophene Adsorption on NiMoS and CoMoS Clusters
}

\author{
Itamar Borges Jr. ${ }^{*, a, b}$ and Alexander M. Silva ${ }^{b}$ \\ ${ }^{a}$ Departamento de Química and ${ }^{b}$ Programa de Pós-Graduação em Engenharia de Defesa, \\ Instituto Militar de Engenharia, Praça General Tibúrcio, 80, Praia Vermelha, \\ Rio de Janeiro-RJ 22290-270, Brazil
}

\begin{abstract}
Um método teórico geral em duas etapas para estudar redistribuições eletrônicas em processos catalíticos é apresentado. Na primeira etapa, teoria do funcional da densidade (DFT) é usada para otimizar completamente duas geometrias: o aglomerado que representa o catalisador e o sistema aglomerado mais molécula adsorvida. Na segunda etapa, a densidade eletrônica molecular convergida é dividida em multipolos centrados em sítios atômicos obtidos segundo uma análise de multipolos distribuídos, que fornece informação topológica detalhada da redistribuição de carga do catalisador e da molécula, antes e depois da adsorção. Esta abordagem é aplicada para a adsorção de tiofeno sobre a borda metálica 1010 dos catalisadores $\mathrm{Ni}(\mathrm{Co}) \mathrm{MoS}$ e comparada com a mesma reação em $\mathrm{MoS}_{2}$ não-substituído. Energias de adsorção, geometrias e a análise de multipolos calculada indicam uma fraca adsorção do tiofeno em ambas as situações. Um modelo coulombiano para a ligação química mostra que a magnitude da ligação metal-enxofre na superfície dos catalisadores de $\mathrm{Ni}(\mathrm{Co}) \mathrm{MoS}$ promovidos é consideravelmente menor do que em $\mathrm{MoS}_{2}$ não substituído, desta forma confirmando a origem do aumento da atividade de hidrodessulfurização (HDS) nestes catalisadores.
\end{abstract}

A general two-step theoretical approach to study electronic redistributions in catalytic processes is presented. In the first step, density functional theory (DFT) is used to fully optimize two geometries: the cluster representing the catalyst and the cluster plus adsorbed molecule system. In the second step, the converged electron density is divided into multipoles centered on atomic sites according to a distributed multipole analysis which provides detailed topological information on the charge redistribution of catalyst and molecule before and after adsorption. This approach is applied to thiophene adsorption on the 1010 metal edge of $\mathrm{Ni}(\mathrm{Co}) \mathrm{MoS}$ catalysts and compared to the same reaction on bare $\mathrm{MoS}_{2}$. Calculated adsorption energies, geometries and multipole analysis indicate weak thiophene chemisorption on both cases. A Coulombic bond model showed that surface metal-sulfur bond strengths in $\mathrm{Ni}(\mathrm{Co}) \mathrm{MoS}$ promoted catalysts are considerably smaller than in bare $\mathrm{MoS}_{2}$, thus confirming the origin of the enhancement of hydrodesulfurization (HDS) activity in these catalysts.

Keywords: charge redistribution, hydrodesulfurization (HDS), promoter effect

\section{Introduction}

Theoretical investigation of molecular processes is usually based on the concept of molecular orbitals (MOs). In most cases, self-consistent, or Hartree-Fock (HF) orbitals, is used. On the other hand, the use of density functional theory (DFT) molecular orbitals is prone to criticism since the Kohn-Sham orbitals, being only a basis set to expand the electron density, lack physical sense. However,

*e-mail: itamar@ime.eb.br although the use of self-consistent MOs definitely enriches interpretation of chemical phenomena, it would be interesting to have a distinct and original perspective. In this work, a physically and chemically motivated method is employed to partition an optimized molecular electron density which, in contrast to self-consistent MOs, includes electron correlation. By investigating the first step in an important hydrotreatment catalytic process, the wealth of detailed information that can be obtained from this general approach is shown.

In hydrotreatment processes such as hydrodesulfurization (HDS), hydrogenation (HYD) and hydrodenitrogenation 
(HDN), promoted catalysts based on molybdenum sulfides are widely used. The most employed HDS catalysts consist of a mixture of Ni or Co with $\mathrm{MoS}_{2}{ }^{1-3}$ Theses mixtures show high HDS activity, whereas mixing other transition metals with $\mathrm{MoS}_{2}$ shows only a weak or moderate promotional effect. ${ }^{4}$ From a fundamental point of view, the structure and function of the active sites, the role of the promoter in the reaction and the hydrogen-activation mechanism, despite recent theoretical and experimental advances, can benefit from new insights. ${ }^{5,6}$ The adsorption geometry and bonding mode of organic molecules on the $\mathrm{MoS}_{2}$-catalyst edge surfaces are also not totally understood. ${ }^{7}$ Therefore, new theoretical work can lead to increased understanding of the relationships between activity and structure of hydrotreatment catalysis, especially at the atomic level.

The $\mathrm{MoS}_{2}$ catalysts, in addition to their importance for HDS processes, have applications as single-layered $\mathrm{MoS}_{2}$ nanotubes, effective solid lubricants, ${ }^{8}$ among others. ${ }^{9}$

A considerable number of experimental and theoretical studies have been devoted to elucidate active sites of bare $\mathrm{MoS}_{2}$ catalysts and to investigate the associated HDS mechanism. In particular, thiophene adsorbed on bare $\mathrm{MoS}_{2}$ is one of the most studied theoretical catalyst models. As a prototype system, thiophene adsorption on $\mathrm{MoS}_{2}$ catalysts has been theoretically investigated using the two available approaches to describe a catalyst in the DFT framework: cluster models of different sizes ${ }^{10-14}$ and periodic boundary conditions. ${ }^{15,16}$

Concerning promoted systems, there are some theoretical works on surface properties and adsorption of molecules on $\mathrm{Ni}(\mathrm{Co}) \mathrm{MoS}$ catalysts using DFT with periodic boundary conditions ${ }^{17-21}$ and cluster models..$^{5,22}$ There are recent reviews on the subject. ${ }^{7,23,24}$ Results from scanning-tunneling-microscopy (STM) experiments ${ }^{25,26}$ and systematic DFT calculations ${ }^{24,27}$ suggest the decoration or Co-Mo-S model as the most probable model of substituted $\mathrm{MoS}_{2}$ catalysts. In this model, $\mathrm{Co}$ or $\mathrm{Ni}$ promoter atoms substitute Mo atoms in the edge planes.

For thiophene and other sulfur molecules adsorbed on Co- and Ni-promoted $\mathrm{MoS}_{2}$ catalysts, quantummechanical calculations are rather scarce, in contrast to adsorption on bare $\mathrm{MoS}_{2}$ catalysts. Sun et al. ${ }^{28}$ calculated, with DFT and periodic boundary conditions, adsorption thermodynamic data of several important molecules, including thiophene, for NiMoS hydrotreatment processes. Weber and van Veen ${ }^{29}$ used DFT to investigate HDS of dibenzothiophene on a NiMoS cluster including one $\mathrm{Ni}$ atom and $18 \mathrm{Mo}$ atoms.

There are few DFT works using topological approaches bearing some similarity to our work, but using different methods. Krebs et al. ${ }^{22}$ studied the adsorption modes of toluene and 2-methylthiophene on $\mathrm{Ni}(\mathrm{Co}) \mathrm{MoS}_{2}$ catalyst and did a topological analysis using electron localization functions (ELF). Joshi et al. ${ }^{30}$ used natural bond orbital (NBO)-based electronic descriptors to describe the adsorption energy variation for 12 sulfur-containing molecules. Aray and Rodríguez ${ }^{31}$ employed DFT and periodic boundary conditions to study the nature of $\mathrm{MoS}_{2}$ edges related to the creation of sulfur vacancies. The same group studied NiMoS using the same approach and electrostatic potential mapping, showing that the main role of the promoter is to produce sulfur-uncovered Lewis acids. ${ }^{32}$ In a preliminary work on the method proposed here, our group studied thiophene molecule adsorption on the $10 \overline{1} 0$ plane (Mo edge) of a $\mathrm{Mo}_{16} \mathrm{~S}_{32}$ cluster applying the distributed multipole analysis (DMA) decomposition. ${ }^{33}$ Recently, also using the DMA method, our group examined $\mathrm{MoS}_{2}$ model clusters of different sizes and concluded that a $\mathrm{Mo}_{16} \mathrm{~S}_{32}$ cluster can adequately represent the electronic structure of real size $\mathrm{MoS}_{2}$ edges. ${ }^{34}$

The purpose of this work is to present a general approach to investigate topological properties of surfaces and reactions. The method is applied to $\mathrm{Ni}(\mathrm{Co}) \mathrm{MoS}$ HDSpromoted catalysts and adsorption of thiophene on their metal edges. A detailed topological picture of the surfaces before and after adsorption is presented. It is also discussed the origin of the promoter effect on both surfaces.

\section{Methodology}

\section{Computational approach}

DFT methods were used in this work. However, the method employed to divide the electron density is independent of the electronic structure approach. Wave function methods such as MP2 can be employed as well.

Calculations were done using the B3LYP functional, ${ }^{35}$ the $\mathrm{LACVP}^{* *}$ basis set $\left(6-31 \mathrm{G}^{* *}\right.$ and effective core potentials for $\mathrm{Ni}$ and $\mathrm{Co}$ ) ${ }^{36}$ and the Gaussian 03 program. ${ }^{37}$ To improve DFT convergence, the G03 default parameters and quadratic convergence (QC) methods were used, the latter recommended for transition metal systems. The Jaguar program ${ }^{38}$ was used with the same method for preliminary convergence tests of the cluster geometries and thiophene desorption. The Jaguar default convergence parameters were employed.

The B3LYP functional was used because thiophene adsorption on bare $\mathrm{MoS}_{2}$ was previously studied with the same method ${ }^{33}$ and to allow comparisons with the present results. However, it is important to take under consideration that dispersion interactions, which can play an important role in adsorption processes, are not well described with B3LYP. ${ }^{39}$ 
Based on the decoration model, the three Mo edge atoms in the $10 \overline{1} 0$ planes were substituted by Co promoter atoms in the CoMoS cluster and by $\mathrm{Ni}$ promoter atoms in NiMoS. In this way, the present results can be compared directly with previous results of thiophene adsorption on a bare $\mathrm{MoS}_{2}$ edge of same size. ${ }^{33}$ Geometry-optimization calculations were carried out to obtain minimum structures of the $\mathrm{Ni}_{3} \mathrm{Mo}_{13} \mathrm{~S}_{32}$ and $\mathrm{Co}_{3} \mathrm{Mo}_{13} \mathrm{~S}_{32}$ isolated clusters before (Figure 1) and after thiophene adsorption (Figure 2). Vibrational frequencies were calculated to check the nature of the stationary points and to discuss the adsorption process.

It should be noted that loading of promoter atoms (that is, the number of $\mathrm{Ni}$ and $\mathrm{Co}$ atoms substituting Mo atoms in the surface) is largely dependent on sulfidation conditions and can be smaller than full substitution. ${ }^{20}$ However, to compare bare $\mathrm{MoS}_{2}$ results $^{33}$ with the present ones and to investigate the promotion effect, we constructed the promoted clusters with this load. For the same reason, we used singlet multiplicity for the calculations.

From DFT calculations on $\mathrm{MoS}_{2}$ clusters, Orita et al. ${ }^{40}$ suggested that 16 metal and 32 sulfur atom cluster models would have the smallest acceptable cluster size for theoretical investigations; also previously shown by our group using the distributed multipole analysis (DMA). ${ }^{34}$ DMA was computed from the DFT one-electron density matrix using the GDMA2 program of Stone. ${ }^{41}$

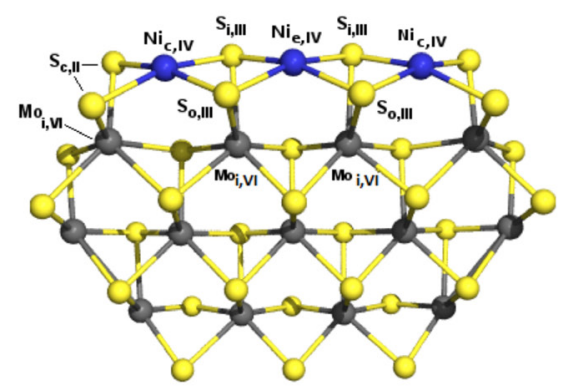

(a) $\mathrm{Ni}_{3} \mathrm{Mo}_{16} \mathrm{~S}_{32}$

Figure 1. Optimized structures of (a) $\mathrm{Ni}_{3} \mathrm{Mo}_{16} \mathrm{~S}_{32}$ and (b) $\mathrm{Co}_{3} \mathrm{Mo}_{13} \mathrm{~S}_{32}$.

\section{Partition of the electron density}

Electron density is a central property. From the fundamental theorem of DFT, the external potential is univocally determined by the electron density. As a corollary, the electron density ultimately determines the wave function. ${ }^{42}$ The electron density either measured or computed can be decomposed in several ways. In this work, it was explored one possibility.

In previous works, our group used the DMA method to study thiophene adsorption on $\mathrm{MoS}_{2},{ }^{33}$ properties of molecules with potential to be new energetic materials ${ }^{43}$ and relations between charge density and sensitivity properties in nitroaromatic molecules. ${ }^{44}$ Recently, our group used another atom-centered partition scheme, the deformed atoms in molecules (DAM) model ${ }^{45,46}$ to partition electron density of four conformers of hexahydro-1,3,5-trinitro1,3,5-triazine energetic molecule, known as RDX, and examined their electronic structure and fragmentation modes. $^{47}$

Partition of the molecular charge according to DMA was developed with the main purpose of evaluating intermolecular interactions, being also useful to investigate accurately molecular charge distributions. ${ }^{41,48-50}$ The method divides the molecular charge density into regions, each one described by its own electric multipole moments.

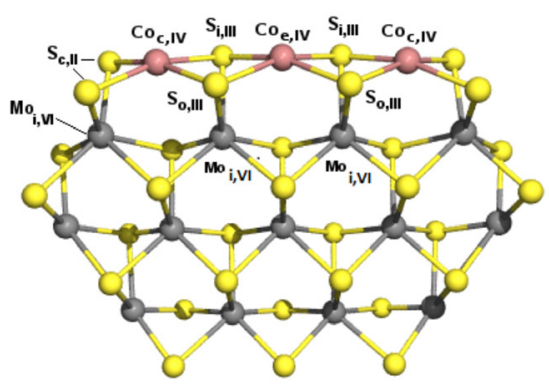

(b) $\mathrm{Co}_{3} \mathrm{Mo}_{13} \mathrm{~S}_{32}$

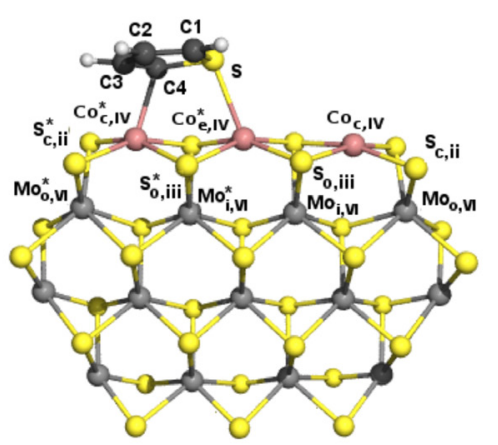

(b) thiophene- $\mathrm{Co}_{3} \mathrm{Mo}_{13} \mathrm{~S}_{32}$

Figure 2. Optimized structures of (a) thiophene- $\mathrm{Ni}_{3} \mathrm{Mo}_{13} \mathrm{~S}_{32}$ and (b) thiophene- $\mathrm{Co}_{3} \mathrm{Mo}_{13} \mathrm{~S}_{32}$. The starred surface atoms are the closest to adsorbed thiophene. 
In this work, a region is an atomic site of the thiophene molecule and the $\mathrm{Ni}(\mathrm{Co}) \mathrm{MoS}$ clusters.

According to DMA, the electron density is divided into a sum of a product of atom-centered Gaussian basis functions, with coefficients determined from the one-electron density matrix. Any individual product of atom-centered basis functions is taken as a sum of multipole moments of ranks up to the degree of its polynomial. Therefore, the overlap of two $s$ functions can be expressed as localized charge (monopole), the product of an $s$ with a $p$ function as a charge plus a dipole, the overlap of two $p$ functions generates charge, dipole and quadrupole moments, and so on. If orbitals are on different atoms, then each pair of Gaussian functions produces a finite electric multipole series at a point between the two atoms determined by exponents of involved Gaussian orbitals. These multipoles are represented by a series on the nearest atom or another expansion site. DMA evaluates these exact representations and approximates each of them by a multipole expansion, usually on the atomic nuclei. This series rapidly converges due to expansion on different points of the electron charge distribution. By combining electron charge densities with nuclei positive charge values, the molecular charge density is obtained, as reported below.

The DMA expansion terms have a clear-cut interpretation. The monopole term corresponds to localized charges on atomic sites; bonds between adjacent atoms with different charge values indicate charge separations. Bond densities result in significant site dipole moments, which depend on the electronegativity of adjacent atoms and their molecular environment. Dipole moments reflect atomic polarization, generally followed by charge separation in the opposite direction. ${ }^{51}$ The quadrupole moment is the first electrostatic moment to include contributions from "out-of-plane density": it is related to delocalized electrons ( $\pi$ electrons) and may have contributions from lone-pair electrons. ${ }^{49}$ Since DMA provides an accurate description of molecular charge densities, the method can be used to study intermolecular interactions and rationalize chemical bonding. ${ }^{33,43,52-54}$

For dipole moments, a vector, it is reported their magnitudes and for quadrupole moments, a tensor, it is presented a number corresponding to the square-root of the sum of all tensor components squared.

The charge distribution of interacting molecules determines their intermolecular interactions, ${ }^{53}$ thus knowing accurately this property allows one to investigate any molecular process in detail. The DMA decomposition, derived from an accurate computed electron density, gives this possibility. It should be noted that DMA is considerably more accurate than methods providing site charges.

\section{Results and Discussion}

The geometry of $\mathrm{Ni}_{3} \mathrm{Mo}_{13} \mathrm{~S}_{32}$ and $\mathrm{Co}_{3} \mathrm{Mo}_{13} \mathrm{~S}_{32}$ clusters

The final $\mathrm{Ni}_{3} \mathrm{Mo}_{13} \mathrm{~S}_{32}$ and $\mathrm{Co}_{3} \mathrm{Mo}_{13} \mathrm{~S}_{32}$ optimized structures are displayed in Figure 1. The decorated metallic $10 \overline{1} 0$ edge of both clusters, with four-coordinated metal atoms, is quasi-planar, in agreement with previous works using DFT and periodic boundary conditions ${ }^{24}$ and a cluster model of same size (but with only one promoted atom in the edge)..$^{5}$

The peripheral edges consist only of $\overline{1} 010$ (S edge) and $10 \overline{1} 0$ planes ( $\mathrm{Ni}$ and Co edges). The decorated edges in this work are only the $10 \overline{1} 0$ metal planes. Different $S$ atoms in both clusters can be classified into two types ${ }^{5,55}$ according to their coordination number and charge properties; they are labelled $\mathrm{S}_{\mathrm{c}, \mathrm{II}}$, and $\mathrm{S}_{\mathrm{o}, \mathrm{II}}$. The $\mathrm{c}$ and o subscripts represent corner and outer atomic positions, and the Roman numeral indicates the coordination number of each atom. Using a similar notation for $\mathrm{Ni}$, Co and Mo, there are corner (c), edge (e) and inner (i) metal atoms (Figure 1). The promoter atoms $\left(\mathrm{Ni}_{\mathrm{c}, \mathrm{IV}}, \mathrm{Ni}_{\mathrm{e}, \mathrm{IV}}\right.$, and $\left.\mathrm{Co}_{\mathrm{c}, \mathrm{IV}}, \mathrm{Co}_{\mathrm{e}, \mathrm{IV}}\right)$ are twofold coordinatively unsaturated (CUS) sites for HDS reactions. ${ }^{5,55}$

The most relevant geometrical parameters of the $\mathrm{Ni}_{3} \mathrm{Mo}_{13} \mathrm{~S}_{32}$ and $\mathrm{Co}_{3} \mathrm{Mo}_{13} \mathrm{~S}_{32}$ clusters are shown in Table 1. These values are compared to experimental $\operatorname{data}^{56,57}$ and calculations of Raybaud et al. ${ }^{18}$ using DFT with periodic boundary conditions. The periodic approach does not show the distortion in the metallic edge present in the cluster model, namely, a slightly distorted local structure around the $\mathrm{Ni}_{\mathrm{c}, \mathrm{IV}}$ and $\mathrm{Co}_{\mathrm{c}, \mathrm{IV}}$ atoms (Table 1). Despite the distortion, distances between metal atoms are in good agreement for both theoretical approaches. The geometric parameters for isolated and adsorbed thiophene molecule on the $\mathrm{Ni}_{3} \mathrm{Mo}_{13} \mathrm{~S}_{32}$ and $\mathrm{Co}_{3} \mathrm{Mo}_{13} \mathrm{~S}_{32}$ clusters can be found in Table 2.

The extended X-ray absorption fine structure (EXAFS) $\mathrm{Ni}-\mathrm{Mo}$ and $\mathrm{Co}-\mathrm{Mo}$ distances ${ }^{56,57}$ are, respectively, 2.85 and $2.80 \AA$, and our $\mathrm{Ni}_{\mathrm{e}, \mathrm{IV}}-\mathrm{Mo}_{\mathrm{i}, \mathrm{VI}}$ and $\mathrm{Co}_{\mathrm{e}, \mathrm{IV}}-\mathrm{Mo}_{\mathrm{i}, \mathrm{VI}}$ computed distances are 2.76 and $2.79 \AA$, respectively, in good agreement with experimental data. The $\mathrm{Ni}_{\mathrm{c}, \mathrm{IV}}-\mathrm{Mo}_{\mathrm{i}, \mathrm{Vl}}$, $\mathrm{Co}_{\mathrm{c}, \mathrm{IV}}-\mathrm{Mo}_{\mathrm{i}, \mathrm{VI}}, \mathrm{Ni}_{\mathrm{c}, \mathrm{IV}}-\mathrm{Mo}_{\mathrm{i}, \mathrm{VI}}$ and $\mathrm{Co}_{\mathrm{c}, \mathrm{IV}}-\mathrm{Mo}_{\mathrm{i}, \mathrm{VI}}$ distances also agree favorably with experiment.

Both $\mathrm{Ni}-\mathrm{S}$ and $\mathrm{Co}-\mathrm{S}$ distances are a bit larger than experimental values, and a slight distortion is also present. Overall, our values for both clusters agree with Raybaud et al. ${ }^{18}$ DFT values despite the slight distortion in the former, which does not have the intrinsic advantage of using periodic boundary conditions. 
Table 1. Geometric parameters for the $\mathrm{Ni}_{3} \mathrm{Mo}_{13} \mathrm{~S}_{32}$ and $\mathrm{Co}_{3} \mathrm{Mo}_{13} \mathrm{~S}_{32}$ clusters

\begin{tabular}{|c|c|c|c|c|}
\hline Parameter & $\mathrm{Ni}_{3} \mathrm{Mo}_{13} \mathrm{~S}_{32}$ & $\mathrm{Co}_{3} \mathrm{Mo}_{13} \mathrm{~S}_{32}$ & Experimental $^{\mathrm{a}}$ & Calculated $^{\mathrm{b}}$ \\
\hline \multicolumn{5}{|l|}{ Distance / $\AA$} \\
\hline $\mathrm{Ni}_{\mathrm{c}, \mathrm{IV}}-\mathrm{Ni}_{\mathrm{e}, \mathrm{IV}}$ & 3.34 & - & - & - \\
\hline $\mathrm{Ni}_{\mathrm{c}, \mathrm{IV}}-\mathrm{Mo}_{\mathrm{o}, \mathrm{VI}}$ & 2.66 & - & 2.85 & 2.75 \\
\hline $\mathrm{Ni}_{\mathrm{c}, \mathrm{IV}}-\mathrm{Mo}_{\mathrm{i}, \mathrm{VI}}$ & 2.86 & - & 2.85 & 2.75 \\
\hline $\mathrm{Ni}_{\mathrm{e}, \mathrm{IV}}-\mathrm{Mo}_{\mathrm{i}, \mathrm{VI}}$ & 2.76 & - & 2.85 & 2.75 \\
\hline $\mathrm{Ni}_{\mathrm{e}, \mathrm{IV}}-\mathrm{Mo}_{\mathrm{o} . \mathrm{VI}}$ & 5.46 & - & - & - \\
\hline $\mathrm{Ni}_{\mathrm{c}, \mathrm{IV}}-\mathrm{S}_{\mathrm{c}, \mathrm{II}}$ & 2.30 & - & - & 2.17 \\
\hline $\mathrm{Ni}_{\mathrm{c}, \mathrm{IV}}-\mathrm{S}_{\mathrm{o}, \mathrm{III}}$ & 2.25 & - & - & 2.17 \\
\hline $\mathrm{Ni}_{\mathrm{e}, \mathrm{IV}}-\mathrm{S}_{\mathrm{o}, \mathrm{III}}$ & 2.25 & - & - & 2.17 \\
\hline $\mathrm{Co}_{\mathrm{c}, \mathrm{IV}}-\mathrm{Co}_{\mathrm{e}, \mathrm{IV}}$ & - & 3.38 & & \\
\hline $\mathrm{Co}_{\mathrm{c}, \mathrm{IV}}-\mathrm{Mo}_{\mathrm{o}, \mathrm{VI}}$ & - & 2.66 & 2.80 & 2.84 \\
\hline $\mathrm{Co}_{\mathrm{c}, \mathrm{IV}}-\mathrm{Mo}_{\mathrm{i}, \mathrm{VI}}$ & - & 2.72 & 2.80 & 2.84 \\
\hline $\mathrm{Co}_{\mathrm{e}, \mathrm{IV}}-\mathrm{Mo}_{\mathrm{i}, \mathrm{VI}}$ & - & 2.79 & 2.80 & 2.84 \\
\hline $\mathrm{Co}_{\mathrm{e}, \mathrm{IV}}-\mathrm{Mo}_{\mathrm{o}, \mathrm{VI}}$ & - & 5.51 & - & - \\
\hline $\mathrm{Co}_{\mathrm{c}, \mathrm{IV}}-\mathrm{S}_{\mathrm{c}, \mathrm{II}}$ & - & 2.27 & $2.18-2.24$ & 2.21 \\
\hline $\mathrm{Co}_{\mathrm{c}, \mathrm{IV}}-\mathrm{S}_{\mathrm{o}, \mathrm{III}}$ & - & 2.27 & $2.18-2.24$ & 2.21 \\
\hline $\mathrm{Co}_{\mathrm{e}, \mathrm{IV}}-\mathrm{S}_{\mathrm{o}, \mathrm{III}}$ & - & 2.31 & $2.18-2.24$ & 2.21 \\
\hline \multicolumn{5}{|l|}{ Angle / degree } \\
\hline $\mathrm{S}_{\mathrm{c}, \mathrm{II}}-\mathrm{Ni}_{\mathrm{c}, \mathrm{IV}}-\mathrm{S}_{\mathrm{c}, \mathrm{II}}$ & 87.1 & - & - & - \\
\hline $\mathrm{S}_{\mathrm{o}, \mathrm{III}}-\mathrm{Ni}_{\mathrm{c}, \mathrm{IV}}-\mathrm{S}_{\mathrm{o}, \mathrm{III}}$ & 82.5 & - & - & - \\
\hline $\mathrm{S}_{\mathrm{o}, \mathrm{III}}-\mathrm{Ni}_{\mathrm{e}, \mathrm{IV}}-\mathrm{S}_{\mathrm{o}, \mathrm{III}}$ & 82.4 & - & - & - \\
\hline $\mathrm{S}_{\mathrm{c}, \mathrm{II}}-\mathrm{Co}_{\mathrm{c}, \mathrm{IV}}-\mathrm{S}_{\mathrm{c}, \mathrm{II}}$ & - & 88.2 & - & - \\
\hline $\mathrm{S}_{\mathrm{o}, \mathrm{III}}-\mathrm{Co}_{\mathrm{c}, \mathrm{IV}}-\mathrm{S}_{\mathrm{o}, \mathrm{III}}$ & - & 83.8 & - & - \\
\hline$\underline{\mathrm{S}_{\mathrm{o}, \mathrm{III}}-\mathrm{Co}_{\mathrm{e}, \mathrm{IV}}-\mathrm{S}_{\mathrm{o}, \mathrm{III}}}$ & - & 82.2 & - & - \\
\hline
\end{tabular}

${ }^{a}$ From references Bouwens et al. ${ }^{56}$ and Leliveld et al .57 bfrom Raybaud et al. ${ }^{18}$

Electronic structure of thiophene, $\mathrm{Ni}_{3} \mathrm{Mo}_{13} \mathrm{~S}_{32}$ and $\mathrm{Co}_{3} \mathrm{Mo}_{13} \mathrm{~S}_{32}$

The calculated charges $\left(\mathrm{Q}_{0}\right)$, dipole $\left(\mathrm{Q}_{1}\right)$ and quadrupole moments $\left(\mathrm{Q}_{2}\right)$ of atoms of the $\mathrm{Ni}_{3} \mathrm{Mo}_{13} \mathrm{~S}_{32}, \mathrm{Co}_{3} \mathrm{Mo}_{13} \mathrm{~S}_{32}$ and $\mathrm{Mo}_{16} \mathrm{~S}_{32}$ clusters and isolated thiophene are shown in Tables S1-S4 in the Supplementary Information (SI) section. The labeling of atoms follows from Figures 1 and 2.

In thiophene (Table S4), carbon atoms bonded to sulfur have the largest negative charges, which are approximately five times larger when compared to the charge of the carbons bonded only to hydrogen. The sulfur atom has an appreciable positive charge, indicating a large $\mathrm{S}^{+} \mathrm{C}^{-}$ charge separation and a considerable dipole value $\left(\mathrm{Q}_{1}\right)$; the nearest carbon atoms are also well polarized. These two results combined reveal a quite general charge-separation bond polarization effect, ${ }^{51}$ thus providing a picture of chemical bond not present in other types of population analysis. The large values of the quadrupole moments in all atoms clearly reflect the well-known thiophenic $\pi$ system.
The dipole values $\left(\mathrm{Q}_{1}\right)$ of atoms in the metallic edge of $\mathrm{Ni}_{3} \mathrm{Mo}_{13} \mathrm{~S}_{32}$ and $\mathrm{Co}_{3} \mathrm{Mo}_{13} \mathrm{~S}_{32}$ (Tables $\mathrm{S} 1$ and S2) are compared with those in bare $\mathrm{MoS}_{2}$ of same size before thiophene adsorption (Table S3: previous results ${ }^{33}$ shown in the same notation).

A dipole value of $0.30 e a_{0}(=0.76 \mathrm{D})$ is about $40 \%$ smaller in comparison to the value of a water molecule $\left(=0.7298 e a_{0}=1.855 \mathrm{D}\right)$. In bare $\mathrm{MoS}_{2}$, corner S atoms have about half the dipole values when compared to corner sulfur atoms in both promoted catalysts, a situation leading to lower interactions in bare $\mathrm{MoS}_{2}$.

For corner metal atoms $\left(\mathrm{Co}_{\mathrm{c}, \mathrm{IV}}\right.$ and $\left.\mathrm{Ni}_{\mathrm{c}, \mathrm{IV}}\right)$, the dipole value of $\mathrm{Co}_{\mathrm{c}, \mathrm{IV}}$ is approximately $40 \%$ higher than in $\mathrm{Ni}_{\mathrm{c}, \mathrm{IV}}$ and 5 times higher than $\mathrm{Mo}_{\mathrm{c}, \mathrm{IV}}$ in bare $\mathrm{MoS}_{2}\left(0.07 e a_{0}\right)$. The dipole value in the $\mathrm{Co}_{\mathrm{e}, \mathrm{IV}}$ edge atom is the largest, being twice the $\mathrm{Ni}_{\mathrm{e}, \mathrm{IV}}$ value and three times the $\mathrm{Mo}_{\mathrm{e}, \mathrm{IV}}$ value, and is similar to the corner cobalt atom $\left(\mathrm{Co}_{\mathrm{c}, \mathrm{IV}}\right)$ value. For sulfur atoms in NiMoS and CoMoS clusters, corner and outer sulfur dipoles have similar values of approximately $0.30 e a_{0}$, the corner $\mathrm{S}$ atoms in pure $\mathrm{MoS}_{2}$ 
Table 2. Geometric parameters for the isolated thiophene and thiophene adsorbed on $\mathrm{Ni}_{3} \mathrm{Mo}_{13} \mathrm{~S}_{32}$ and $\mathrm{Co}_{3} \mathrm{Mo}_{13} \mathrm{~S}_{32}$ clusters

\begin{tabular}{|c|c|c|c|c|}
\hline \multirow{2}{*}{ Parameter } & \multicolumn{2}{|c|}{ Isolated thiophene } & \multicolumn{2}{|c|}{ Adsorbed thiophene } \\
\hline & Experimental & Calculated & $\mathrm{Ni}_{3} \mathrm{Mo}_{16} \mathrm{~S}_{32}$ & $\mathrm{Co}_{3} \mathrm{Mo}_{16} \mathrm{~S}_{32}$ \\
\hline \multicolumn{5}{|l|}{ Distance / Å } \\
\hline $\mathrm{S}-\mathrm{C} 1$ & 1.71 & 1.73 & 1.74 & 1.76 \\
\hline $\mathrm{S}-\mathrm{C} 4$ & 1.71 & 1.73 & 1.72 & 1.79 \\
\hline $\mathrm{C} 1-\mathrm{C} 2$ & 1.37 & 1.37 & 1.36 & 1.35 \\
\hline $\mathrm{C} 2-\mathrm{C} 3$ & 1.42 & 1.43 & 1.44 & 1.45 \\
\hline $\mathrm{C} 3-\mathrm{C} 4$ & 1.37 & 1.37 & 1.39 & 1.39 \\
\hline $\mathrm{S}-\mathrm{Ni}_{\mathrm{e}, \mathrm{IV}}^{*}$ & - & - & 3.64 & - \\
\hline $\mathrm{C} 2-\mathrm{Ni}_{\mathrm{c}, \mathrm{IV}}^{*}$ & - & - & 3.20 & - \\
\hline $\mathrm{C} 3-\mathrm{Ni}_{\mathrm{c}, \mathrm{IV}}{ }^{*}$ & - & - & 2.43 & - \\
\hline $\mathrm{C} 4-\mathrm{Ni}_{\mathrm{c}, \mathrm{IV}}{ }$ & - & - & 2.65 & - \\
\hline $\mathrm{Ni}_{\mathrm{c}, \mathrm{IV}}{ }^{*}-\mathrm{Ni}_{\mathrm{e}, \mathrm{IV}}$ & - & - & 3.36 & - \\
\hline $\mathrm{Ni}_{\mathrm{c}, \mathrm{IV}}^{*}-\mathrm{Mo}_{\mathrm{i}, \mathrm{VI}}$ & - & - & 2.73 & - \\
\hline $\mathrm{Ni}_{\mathrm{c}, \mathrm{IV}}^{*}-\mathrm{Mo}_{\mathrm{i}, \mathrm{VI}}$ & - & - & 2.88 & - \\
\hline $\mathrm{Ni}^{*}{ }_{c, I V}-\mathrm{S}_{\mathrm{c}, \mathrm{II}}$ & - & - & 2.30 & - \\
\hline $\mathrm{Ni}^{*}{ }_{c, I V}-\mathrm{S}_{\mathrm{o}, \mathrm{III}}$ & - & - & 2.28 & - \\
\hline $\mathrm{Ni}_{\mathrm{c}, \mathrm{IV}}^{*}-\mathrm{S}_{\mathrm{i}, \mathrm{III}}$ & - & - & 2.27 & - \\
\hline $\mathrm{S}-\mathrm{Co}_{\mathrm{e}, \mathrm{IV}}$ & - & - & - & 2.51 \\
\hline $\mathrm{C} 2-\mathrm{Co}_{\mathrm{c}, \mathrm{IV}}^{*}$ & - & - & - & 3.25 \\
\hline $\mathrm{C} 3-\mathrm{Co}_{\mathrm{c}, \mathrm{IV}}{ }^{*}$ & - & - & - & 2.39 \\
\hline $\mathrm{C} 4-\mathrm{Co}_{\mathrm{c}, \mathrm{IV}}^{*}$ & - & - & - & 2.22 \\
\hline $\mathrm{Co}_{\mathrm{c}, \mathrm{IV}}^{*}-\mathrm{Co}_{\mathrm{e}, \mathrm{IV}}$ & - & - & - & 3.25 \\
\hline $\mathrm{Co}_{\mathrm{c}, \mathrm{IV}}^{*}-\mathrm{Mo}_{\mathrm{i}, \mathrm{VI}}$ & - & - & - & 2.73 \\
\hline $\mathrm{Co}_{\mathrm{c}, \mathrm{IV}}^{*}-\mathrm{Mo}_{\mathrm{i}, \mathrm{VI}}$ & - & - & - & 2.81 \\
\hline $\mathrm{Co}_{\mathrm{c}, \mathrm{IV}}^{*}-\mathrm{S}_{\mathrm{c}, \mathrm{II}}$ & - & - & - & 2.27 \\
\hline $\mathrm{Co}_{\mathrm{c}, \mathrm{IV}}^{*}-\mathrm{S}_{\mathrm{o}, \mathrm{III}}$ & - & - & - & 2.28 \\
\hline $\mathrm{Co}_{\mathrm{c}, \mathrm{IV}}^{*}-\mathrm{S}_{\mathrm{i}, \mathrm{III}}$ & - & - & - & 2.28 \\
\hline
\end{tabular}

bear a comparable value $\left(0.29 e a_{0}\right)$ while the outer $\mathrm{S}$ atoms have about half of that value $\left(0.16 e a_{0}\right)$.

In previous work, ${ }^{33}$ our group verified that, after thiophene adsorption, site dipole moment values of $\mathrm{S}$ and Mo atoms in the Mo edge plane of bare $\mathrm{MoS}_{2}$ increased substantially. In particular, in bare $\mathrm{MoS}_{2}$ dipole moments of Mo surface atoms in the region over adsorbed thiophene increased by a factor of 10 and those of corner $\mathrm{S}$ atoms almost doubled. Moreover, dipole values of carbon atoms next to the sulfur atom of adsorbed thiophene increased by about $30 \%$.

Considering thiophene adsorption on promoted catalysts, dipole values before and after adsorption in the sulfur sites do not show any appreciable variation (Tables S5 and S6 in the SI section), in contrast to thiophene adsorbed on bare $\mathrm{MoS}_{2}$. On the other hand, dipole values of $\mathrm{Ni}$ and $\mathrm{Co}$ atoms closer to adsorbed thiophene $\left(\mathrm{Ni}_{\mathrm{c}, \mathrm{IV}}{ }^{*}, \mathrm{Ni}_{\mathrm{e}, \mathrm{IV}}{ }^{*}, \mathrm{Co}_{\mathrm{c}, \mathrm{IV}}{ }^{2}\right.$ and $\left.\mathrm{Co}_{\mathrm{e}, \mathrm{IV}}{ }^{*}\right)$ exhibit considerable variation. For example, dipole value of corner $\mathrm{Ni}$ and edge Co atoms increased from 0.27 to $0.52 e a_{0}$ and from 0.38 to $0.54 e a_{0}$, respectively. Concerning the adsorbed thiophene on both surfaces, there are not substantial changes in the dipole values of $\mathrm{C}$ atoms and only a small variation for the $\mathrm{S}$ atom. This small variation is more apparent in the thiophene plus $\mathrm{Co}_{3} \mathrm{Mo}_{13} \mathrm{~S}_{32}$ system, a pattern quite distinct when compared to thiophene adsorbed on bare $\operatorname{MoS}_{2}{ }^{33}$

According to the literature, the role of promoter atoms in improving the catalyst activity derives from reducing the average metal-sulfur $(\mathrm{M}-\mathrm{S})$ bond strength. The $\mathrm{Co}-\mathrm{S}$ and $\mathrm{Ni}-\mathrm{S}$ bonds, being weaker than a Mo-S bond, are broken more easily and result in increased number of vacancies in the edges. ${ }^{18}$ This behavior can be explained as follows.

From Tables S1 and S2, it can be seen that both corner and edge $\mathrm{Ni}$ and $\mathrm{Co}$ atoms have negative charges $\left(\mathrm{Q}_{0}\right)$, with values about $25 \%$ more negative in Ni-promoted cluster. On the other 
hand, charges on Mo atoms in a bare $\mathrm{MoS}_{2}$ cluster of same size (Table S3) are positive and more than three times the magnitude of metal atoms ( $\mathrm{Ni}$ and $\mathrm{Co}$ ) of promoted cluster. The negative charges in the $\mathrm{Ni}$ and $\mathrm{Co}$ atoms are followed, according to their $\mathrm{Q}_{1}$ values, by considerable site polarization in comparison to bare $\mathrm{MoS}_{2}$. All sulfur atoms in the three metal edges present negative charges, with the largest values being for $\mathrm{S}$ atoms in bare $\mathrm{MoS}_{2}$ cluster.

In order to describe the nature of the bond strengths and provide quantitative information, a Coulombic bonding model can be used. ${ }^{58,59}$ In this way, consider that: $(i)$ bond strengths are dominated by Coulombic interactions between DMA charges and thus are ion-ion like; (ii) only nearest-neighbor surface atoms contribute to the bond strength; (iii) distances between atoms are similar and; (iv) contributions from inner atoms to bond strengths are similar for the three clusters.

The promoter and sulfur atoms in both substituted clusters have negative charges. Note that charges are the localized part of decomposed charge densities, so there are also dipole and quadrupole moment contributions to fully describe the site density. Therefore, negative charges on the $\mathrm{Ni}$ and $\mathrm{Co}$ atom are possible in the DMA framework.

In contrast to promoted clusters, bare $\mathrm{MoS}_{2}$ cluster has Mo atoms with positive charges and $\mathrm{S}$ atoms with negative charges; moreover, bare $\mathrm{MoS}_{2}$ has the largest magnitude of charge values. Therefore, by substituting the computed DMA charges into the expression of the Coulombic interaction energy, it can be seen directly that ion-ion contribution to the bond strengths is positive in promoted clusters (i.e., repulsive for like-charges) and negative (i.e., attractive for opposite charges) in bare $\mathrm{MoS}_{2}$. This situation clearly indicates decreased metal-sulfur bond strengths in promoted clusters in comparison to bare $\mathrm{MoS}_{2}$, thus confirming theoretically the bond weakening as the origin of the promoter effect. Furthermore, since the magnitude of negative charges in the $\mathrm{Ni}$ and $\mathrm{S}$ atoms of Ni-promoted edge is larger than charges on $\mathrm{Co}$ and $\mathrm{S}$ atoms in the metal edge, NiMoS catalyst has the smallest bond strengths and thus produces vacancies more easily, thereby being the most effective catalyst, as actually happens. ${ }^{17}$ Naturally, this Coulombic model could be improved, in the context of DMA multipoles, by including ion-dipole, dipole-dipole and even higher multipole terms. However, these contributions would be considerably smaller, ${ }^{60}$ very complicated to calculate and would not change the reasoning just given.

These results are in nice agreement with Allred and Rochow (A.E.) electronegativity scale, defined as the electrostatic force exerted by a nucleus on the valence electrons. ${ }^{61}$ In other words, the A.E. scale is the charge experienced by an electron on the "surface" of an atom: the larger the charge per unit area of the atomic surface, the greater the tendency of that atom to attract electrons. Therefore, the A.E. scale is constructed according to similar ideas of the Coulombic model just discussed. So, not surprisingly, in the A.E. scale, the Mo atom is the less electronegative. Moreover, the A.E. electronegativity values are 1.30 for $\mathrm{Mo}, 1.7$ for $\mathrm{Co}$ and 1.75 for $\mathrm{Ni}$, with sulfur having a value of 2.44 .

The interaction of adsorbed thiophene with promoted clusters is not as strong as with bare $\mathrm{MoS}_{2}$, a picture which can be understood from the DMA. There are negative charges $\left(\mathrm{Q}_{0}\right)$ on $\mathrm{Ni}$ and Co surface atoms of promoted clusters and positive charges on Mo atoms of bare $\mathrm{MoS}_{2}$. Additionally, quadrupole moments $\left(\mathrm{Q}_{2}\right)$ for Mo atoms in bare $\mathrm{MoS}_{2}$ are considerably larger than in $\mathrm{Ni}$ and $\mathrm{Co}$ atoms of promoted catalysts. Thus, the $\mathrm{Q}_{0}$ and $\mathrm{Q}_{2}$ values favor thiophene-surface interaction in bare (non-promoted) $\mathrm{MoS}_{2}$. In contrast, dipole $\left(\mathrm{Q}_{1}\right)$ values of corner $\mathrm{Ni}$ and $\mathrm{Co}$ atoms are about four times larger than in Mo atoms of bare $\mathrm{MoS}_{2}$; for edge atoms, $\mathrm{Q}_{1}$ values for Co are over three times and for $\mathrm{Ni}$ are 50\% larger than in bare $\mathrm{MoS}_{2}$. These dipole values indicate considerable site polarization of metal atoms in promoted catalysts in comparison to bare $\mathrm{MoS}_{2}$. Therefore, a more localized bonding of adsorbed thiophene to surface atoms is favored in promoted clusters. Furthermore, our results show that thiophene-surface interaction in promoted catalysts is insufficient to destroy the molecular $\pi$ system. In contrast, thiophene adsorbed on bare $\mathrm{MoS}_{2}$ interacts with the surface through its $\pi$ electron system, thereby leading to the non-localized $\eta_{5}$ bonding. ${ }^{33}$

Inner and outer Mo atoms in the three clusters reveal in general similar multipoles values. The exception is the polarization $\left(\mathrm{Q}_{1}\right)$ of inner and outer Mo atoms in bare $\mathrm{MoS}_{2}$, which is smaller than in promoted clusters, specially for $\mathrm{Mo}_{\mathrm{i}, \mathrm{VI}}$ (inner) atoms in the former. The quadrupole $\left(\mathrm{Q}_{2}\right)$ value in the $\mathrm{Mo}_{\mathrm{i}, \mathrm{VI}}$ site of bare $\mathrm{MoS}_{2}$ is also much smaller. These multipole values show that these "missing" polarization and delocalized electrons in inner $\mathrm{Mo}\left(\mathrm{Mo}_{\mathrm{i}, \mathrm{VI}}\right)$ probably contribute to greater electron density on the surface $\mathrm{S}$ atoms in bare $\mathrm{MoS}_{2}$, in comparison to equivalent $\mathrm{S}$ atoms in promoted clusters.

Thiophene adsorption on the $\mathrm{Ni}_{3} \mathrm{Mo}_{13} \mathrm{~S}_{32}$ and $\mathrm{Co}_{3} \mathrm{Mo}_{13} \mathrm{~S}_{32}$ clusters

Experimental studies of desulfurization reactions on metal surfaces and with organometallic complexes ${ }^{62}$ show that the orientation of thiophene with respect to metal surfaces depends on the coverage of co-adsorbed hydrocarbons and sulfur atoms. On most surfaces, a parallel 
geometry $\left(\eta^{5}\right)$ is favored for low surface coverage while a more perpendicular ring orientation $\left(\eta^{1}\right)$ is favored at high surface coverage. Quantum-mechanical calculations using DFT combined with cluster or periodic boundary condition models ${ }^{15,16,33,40}$ show that $\eta^{5}$-type adsorption mode of thiophene is the most stable when a perfect metallic edge is considered. Therefore, we have limited ourselves only to starting configurations of thiophene parallel to the surface for geometry optimizations. However, we should bear in mind that, under catalytic conditions, the metallic edge is covered with bridged sulfur atoms ${ }^{34}$ and the most favorable adsorption mode on this surface is a $\eta^{1}$ mode. ${ }^{16}$

The optimized configurations of adsorbed thiophene on the $\mathrm{Ni}_{3} \mathrm{Mo}_{13} \mathrm{~S}_{32}$ and $\mathrm{Co}_{3} \mathrm{Mo}_{13} \mathrm{~S}_{32}$ model catalysts are shown in Figure 2. The starred surface atoms are the closest to adsorbed thiophene molecule.

Thiophene adsorbs on the metallic edge of $\mathrm{Ni}_{3} \mathrm{Mo}_{13} \mathrm{~S}_{32}$ through two carbon atoms, C3 and C4 (Figure 2a), in a $\eta^{2}$ mode. The $\mathrm{Ni}^{*}{ }_{\mathrm{c}, \mathrm{IV}}-\mathrm{C} 3$ and $\mathrm{Ni}^{*}{ }_{\mathrm{c}, \mathrm{IV}}-\mathrm{C} 4$ bond distances are 2.43 and $2.65 \AA$, respectively. The planarity of the thiophene ring and thus, its $\pi$ system, is preserved, in contrast to what happens for thiophene adsorption on the metallic edge of bare $\mathrm{MoS}_{2} \cdot{ }^{15,33}$ Furthermore, the converged thiophene geometry after adsorption does present substantial changes. The surface multipole values of the Ni-promoted cluster discussed in the last section, which almost did not vary, confirm this trend; the same behavior also exists for thiophene adsorbed on Co-promoted cluster. This result is further corroborated from the small variations of thiophene multipoles before and after adsorption. The exception is the $\mathrm{C} 3$ atom, bonded to $\mathrm{Ni}_{\mathrm{c}, \mathrm{IV}}{ }_{\mathrm{H}}$ and the thiophene atom closest to the surface: the charges $\left(\mathrm{Q}_{0}\right)$ almost double and the dipole $\left(Q_{1}\right)$ increases by a factor over 5 , an indication of combined charge separation and bond polarization of the $\mathrm{C}=\mathrm{C}$ bond in thiophene. Thus, some bond weakening is induced by the surface through localized backdonation.

Regarding the Ni surface after thiophene adsorption, the prominent features are the polarization of $\mathrm{Ni}_{\mathrm{c}, \mathrm{IV}}{ }^{*} \mathrm{Q}_{1}$ almost doubles) and an over $20 \%$ increase of its quadrupole $\left(\mathrm{Q}_{2}\right)$ value. Both results indicate a localized electron donation from the molecule to the surface. The quadrupole of $\mathrm{Ni}_{\mathrm{e}, \mathrm{IV}}{ }$ atom increases, while dipole and charge values do not change. These features reflect the presence of an interaction between delocalized NiMoS surface electrons and adsorbed thiophene. Concerning edge sulfur atoms, including those nearest to thiophene, the multipoles do not change significantly, a further indication of the preponderance of the role of edge metal atoms in thiophene-surface interaction.

When thiophene adsorption on the metallic edge of $\mathrm{Co}_{3} \mathrm{Mo}_{13} \mathrm{~S}_{32}$ is analyzed, some similarity with the adsorption on $\mathrm{Ni}_{3} \mathrm{Mo}_{13} \mathrm{~S}_{32}$ can be seen. Thiophene also adsorbs on the
$\mathrm{Co}_{3} \mathrm{Mo}_{13} \mathrm{~S}_{32}$ cluster through two carbon atoms, $\mathrm{C} 3$ and $\mathrm{C} 4$ but, unlike $\mathrm{Ni}$ catalyst, there is an evident $\mathrm{S}$ bonding to the surface. This bond type can be classified as $\eta^{2}-C$ and $\eta^{1}-\mathrm{S}$. The $\mathrm{Co}_{\mathrm{c}, \mathrm{IV}}-\mathrm{C} 3, \mathrm{Co}_{\mathrm{c}, \mathrm{IV}}-\mathrm{C} 4$ and $\mathrm{Co}_{\mathrm{e}, \mathrm{IV}}-\mathrm{S}$ bond distances are $2.39,2.22$ and $2.51 \AA$, respectively (Table 2). The major changes of multipole values in thiophene before (Table S4) and after adsorption (Table S6) are as follows. The quadrupole values of $\mathrm{C} 4$ (changes from 1.68 to $1.27 e a^{2}{ }_{0}$ ) and $\mathrm{C} 1$ (from 1.68 to $1.47 e a^{2}$ ) atoms decrease. For the $\mathrm{S}$ atom in thiophene, the charge increases (from 0.63 to $0.73 e$ ) and the dipole and quadrupole decreases (from 1.19 to $0.91 e a_{0}$ and 2.03 to $1.39 e a_{0}^{2}$, respectively). These results indicate charge donation from the molecule to the $\mathrm{Co}_{3} \mathrm{Mo}_{13} \mathrm{~S}_{32}$ edge and interaction between $\pi$ electrons of thiophene and the same edge, with some charge transfer to the molecule (backdonation). The picture is further supported by analysis of surface Co atoms: charge and quadrupole values of the $\mathrm{Co}_{\mathrm{e}, \mathrm{IV}}{ }_{\mathrm{r}}$ atom, bounded to the $\mathrm{S}$ atom of thiophene increase and the quadrupole value of $\mathrm{Co}_{\mathrm{c}, \mathrm{IV}}$, bonded to the $\mathrm{C} 4$ atom of thiophene, also increases due to the electron donation from the molecule to the surface. Similarly to adsorption on the Ni surface, the results indicate $\mathrm{C}=\mathrm{C}$ bond weakening.

Increase of $\mathrm{C}=\mathrm{C}$ dipole value in both thiophene adsorption processes indicates a localized induced polarization, thus reflecting a weakening of these bonds, in agreement with increased bond stretches seen in the vibrational analysis, to be discussed.

To summarize, the results for thiophene adsorbed on promoted clusters indicate some interaction between the thiophene $\pi$ electrons and the surfaces, though not as strong as in bare $\operatorname{MoS}_{2}{ }^{33}$ Some charge donation from the thiophene molecule to the promoted surfaces is also present. In both cases, the adsorption mode is weaker chemisorption than on bare $\mathrm{MoS}_{2}$, an indication of the lower probability of a direct HDS process.

\section{Adsorption energies and harmonic frequencies}

Adsorption energies were computed by subtracting the optimized gas-phase thiophene and cluster energies from the energy of the optimized thiophene/cluster complex according to:

$\mathrm{E}_{\mathrm{ad}}=\mathrm{E}_{\text {thiophene/cluster }}-\mathrm{E}_{\text {thiophene }}-\mathrm{E}_{\text {cluster }}$

For the $\mathrm{Ni}_{3} \mathrm{Mo}_{13} \mathrm{~S}_{32}$ cluster, the computed adsorption energy is $13.7 \mathrm{kcal} \mathrm{mol}^{-1}$, including zero-point-energy corrections. This value is in agreement with a periodic DFT calculation ${ }^{28}$ yielding $11.5 \mathrm{kcal} \mathrm{mol}^{-1}$; a similar orientation of the adsorbed thiophene molecule on the metal edge was 
Table 3. Vibrational frequencies $\left(\mathrm{cm}^{-1}\right)$ for the isolated thiophene and thiophene adsorbed on the $\mathrm{Ni}_{3} \mathrm{Mo}_{13} \mathrm{~S}_{32}$ and $\mathrm{Co}_{3} \mathrm{Mo}_{13} \mathrm{~S}_{32}$ clusters. The second set of numbers in parenthesis in the NiMoS- and CoMoS-adsorption columns are the shifts with respect to calculated frequencies of the free molecule

\begin{tabular}{|c|c|c|c|c|}
\hline \multirow[b]{2}{*}{ Assignment } & \multirow{2}{*}{$\begin{array}{c}\text { Experimental } \\
\text { (free molecule) }\end{array}$} & \multicolumn{3}{|c|}{ Calculated } \\
\hline & & Free molecule & $\begin{array}{c}\eta^{2}-\mathrm{C} \text { adsorption } \\
(\text { NiMoS })\end{array}$ & $\begin{array}{c}\eta^{2}-\mathrm{C} \text { and } \eta^{1}-\mathrm{S} \text { adsorption } \\
(\mathrm{CoMoS})\end{array}$ \\
\hline$v(\mathrm{C}-\mathrm{H})$ & 3126 & 3284 & $3276(-4)$ & $3280(-8)$ \\
\hline$v(\mathrm{C}-\mathrm{H})$ & 3125 & 3282 & $3271(-11)$ & $3271(-11)$ \\
\hline$v(\mathrm{C}-\mathrm{H})$ & 3098 & 3231 & $3241(+10)$ & $3241(+10)$ \\
\hline$v(\mathrm{C}-\mathrm{H})$ & 3098 & 3219 & $3229(+10)$ & $3229(+10)$ \\
\hline$v(\mathrm{C}=\mathrm{C})$ asym & 1507 & 1594 & $1554(-40)$ & $1530(-64)$ \\
\hline$v(\mathrm{C}=\mathrm{C})$ sym & 1409 & 1491 & $1441(-50)$ & $1423(-68)$ \\
\hline$v$ (ring) & 1360 & 1399 & $1392(-7)$ & $1390(-9)$ \\
\hline$\delta(\mathrm{C}-\mathrm{H})$ & 1256 & 1276 & $1277(+1)$ & $1277(+1)$ \\
\hline$\delta(\mathrm{C}-\mathrm{H})$ & 1085 & 1120 & $1118(-2)$ & $1118(-2)$ \\
\hline$\delta(\mathrm{C}-\mathrm{H})$ & 1083 & 1115 & $1104(-11)$ & $1104(-11)$ \\
\hline$v$ (ring) & 1036 & 1051 & $1044(-7)$ & $1048(-3)$ \\
\hline
\end{tabular}

also obtained. DFT calculations by Orita et $a l .{ }^{5}$ using a $\mathrm{Ni}_{1} \mathrm{Mo}_{15} \mathrm{~S}_{32}$ cluster with the metallic edge having two Mo atoms on the corners and only a central $\mathrm{Ni}$ atom show that, for thiophene adsorbed vertically, the computed adsorption energy is $7.8 \mathrm{kcal} \mathrm{mol}^{-1}$. Therefore, similarly to thiophene adsorption on bare $\mathrm{MoS}_{2},{ }^{15,16,33,40}$ the most favorable modes for a fully promoted metal edge are parallel to the metallic edge.

The calculated adsorption energy of thiophene molecule adsorbed on the $\mathrm{Co}_{3} \mathrm{Mo}_{13} \mathrm{~S}_{32}$ cluster is $37.1 \mathrm{kcal} \mathrm{mol}^{-1}$, including zero-point-energy corrections. Therefore, this process is more exothermic than adsorption on $\mathrm{Ni}_{3} \mathrm{Mo}_{13} \mathrm{~S}_{32}$. It was not possible to find previous results for thiophene adsorbed on promoted Co catalysts to compare.

Harmonic vibrational frequencies are shown in Table 3. Unscaled gas-phase thiophene vibrational frequencies were computed with the same Gaussian basis set used in this work, including the same pseudo-potentials, to allow consistent comparison with adsorbed thiophene. The comparison of the vibrational frequencies of adsorbed and gas-phase thiophene shows the most important changes occurring in the $\mathrm{C}=\mathrm{C}$ stretching modes: shifts with respect to calculated frequencies of the free molecule are -50 and $-40 \mathrm{~cm}^{-1}$ for the symmetric and asymmetric modes in NiMoS adsorption and -64 and $-8 \mathrm{~cm}^{-1}$ for the symmetric and asymmetric modes in CoMoS adsorption, respectively. This decrease of the stretching frequencies of adsorbed thiophene may be related to participation of thiophene $\pi$ electrons in the bonds formed between thiophene carbon atoms and the metal surface atoms, as identified according to the partition analysis of the charge density described before.
The frequency shifts of thiophene adsorbed on the promoted systems are substantially smaller than for thiophene adsorbed on bare $\mathrm{MoS}_{2} \cdot{ }^{16,33}$ This finding provides a further confirmation of the weaker activation of adsorbed thiophene on metal edges of NiMoS and CoMoS catalysts when compared to adsorption on the same edge of bare $\mathrm{MoS}_{2}$.

\section{Conclusions}

The adsorption of thiophene on clean metal edges of promoted $\mathrm{MoS}_{2}$ catalysts, described by $\mathrm{Ni}_{3} \mathrm{Mo}_{13} \mathrm{~S}_{32}$ and $\mathrm{Co}_{3} \mathrm{MO}_{13} \mathrm{~S}_{32}$ clusters, was investigated using DFT. A $\eta^{2}$ coordination type of thiophene adsorbed on the $\mathrm{Ni}_{3} \mathrm{Mo}_{13} \mathrm{~S}_{32}$ cluster and a $\eta^{2}-C$ and $\eta^{1}-S$ mode for adsorption on the $\mathrm{Co}_{3} \mathrm{Mo}_{13} \mathrm{~S}_{32}$ cluster was found after geometry optimization with full relaxation of the coordinates. Computed adsorption energies and final geometries, including zeropoint-energy corrections, indicate a weak chemisorption of thiophene molecule on the metallic edge of the $\mathrm{Ni}_{3} \mathrm{Mo}_{13} \mathrm{~S}_{32}$ cluster and a regular chemisorption on the $\mathrm{Co}_{3} \mathrm{Mo}_{13} \mathrm{~S}_{32}$ cluster. Vibrational frequencies and intensities were calculated, and the most important shifts were found for thiophene $\mathrm{C}=\mathrm{C}$ bonds. Both shifts are lower than for thiophene adsorbed on bare $\mathrm{MoS}_{2}$.

From a Coulombic model of bonding strengths using the computed DMA charges, it was possible to show that metal-sulfur bond strengths in the metal edge of promoted catalysts are lower than in bare $\mathrm{MoS}_{2}$, thereby confirming the origin of promoter effect as a weakening of surface metal-S bonds.

Geometric, vibrational and electronic results of this work provided a consistent picture of thiophene adsorption 
on Ni- and $\mathrm{CoMoS}_{2}$-promoted catalysts. Moreover, our approach using the distributed multipole analysis offers the possibility for detailed scrutiny of charge density modifications in molecular processes.

\section{Supplementary Information}

Tables S1-S6 of computed multipole values of the studied molecular systems are available free of charge at http:// jbcs.sbq.org.br as PDF file.

\section{Acknowledgements}

The authors thank Conselho Nacional de Desenvolvimento Científico e Tecnológico (CNPq), Fundação de Amparo à Pesquisa do Estado do Rio de Janeiro (FAPERJ) and the Brazilian Army for financial support of this research. A. M. S. thanks Fundação Ricardo Franco, supporter of IME, for a Post-Doc scholarship. We also thank Prof. M. A. C. Nascimento for availability of the JAGUAR program.

\section{References}

1. Prins, R.; Debeer, V. H. J.; Somorjai, G. A.; Catal. Rev.: Sci. Eng. 1989, 31, 1.

2. Startsev, A. N.; Catal. Rev.: Sci. Eng. 1995, 37, 353.

3. Oyama, S. T.; Gott, T.; Zhao, H. Y.; Lee, Y. K.; Catal. Today 2009, 143, 94.

4. Chianelli, R. R.; Pecoraro, T. A.; Halbert, T. R.; Pan, W. H.; Stiefel, E. I.; J. Catal. 1984, 86, 226.

5. Orita, H.; Uchida, K.; Itoh, N.; Appl. Catal., A 2004, 258, 115.

6. Kogan, V. M.; Nikulshin, P. A.; Catal. Today 2010, 149, 224.

7. Sun, M.Y.;Adjaye, J.; Nelson,A. E.; Appl. Catal., A 2004, 263, 131.

8. Bollinger, M. V.; Jacobsen, K. W.; Nørskov, J. K.; Phys. Rev. B: Condens. Matter Mater. Phys. 2003, 67, 085410.

9. Tenne, R.; Remskar, M.; Enyashin, A.; Seifert, G. In Carbon Nanotubes - Topics in Applied Physiscs 111; Jorio, A.; Dresselhaus, G.; Dresselhaus, M. S., eds.; Springer-Verlag Berlin: Berlin, Germany, 2008, p. 631.

10. Diez, R. P.; Jubert, A. H.; J. Mol. Catal. 1992, 73, 65.

11. Gainza, A. E.; Rodriguezarias, E. N.; Ruette, F.; J. Mol. Catal. 1993, 85, 345.

12. Chen, R.; Xin, Q.; Wang, C. D.; J. Mol. Catal. 1994, 89, 345.

13. Teraishi, K.; J. Mol. Catal. A: Chem. 1997, 126, 73.

14. Yao, X. Q.; Li, Y. W.; Jiao, H. J.; J. Mol. Struct. THEOCHEM 2005, 726, 81.

15. Raybaud, P.; Hafner, J.; Kresse, G.; Toulhoat, H.; Phys. Rev. Lett. 1998, 80, 1481.

16. Cristol, S.; Paul, J. F.; Schovsbo, C.; Veilly, E.; Payen, E.; J. Catal. 2006, 239, 145.
17. Byskov, L. S.; Norskov, J. K.; Clausen, B. S.; Topsoe, H.; J. Catal. 1999, 187, 109.

18. Raybaud, P.; Hafner, J.; Kresse, G.; Kasztelan, S.; Toulhoat, H.; J. Catal. 2000, 190, 128.

19. Travert, A.; Nakamura, H.; van Santen, R. A.; Cristol, S.; Paul, J. F.; Payen, E.; J. Am. Chem. Soc. 2002, 124, 7084.

20. Sun, M. Y.; Nelson, A. E.; Adjaye, J.; J. Catal. 2004, 226, 32.

21. Chen, Y. Y.; Dong, M.; Wang, J. G.; Jiao, H. J.; J. Phys. Chem. C 2010, 114, 16669.

22. Krebs, E.; Silvi, B.; Raybaud, P.; J. Chem. Theory Comput. 2009, 5,580 .

23. Raybaud, P.; Appl. Catal. A Gen. 2007, 322, 76.

24. Paul, J. F.; Cristol, S.; Payen, E.; Catal. Today 2008, 130, 139.

25. Lauritsen, J. V.; Helveg, S.; Laegsgaard, E.; Stensgaard, I.; Clausen, B. S.; Topsoe, H.; Besenbacher, E.; J. Catal. 2001, $197,1$.

26. Kibsgaard, J.; Tuxen, A.; Knudsen, K. G.; Brorson, M.; Topsoe, H.; Laegsgaard, E.; Lauritsen, J. V.; Besenbacher, F.; J. Catal. 2010, 272, 195.

27. Krebs, E.; Daudin, A.; Raybaud, P.; Oil Gas Sci. Technol. 2009, 64, 707.

28. Sun, M. Y.; Nelson, A. E.; Adjaye, J.; Catal. Lett. 2006, 109, 133.

29. Weber, T.; van Veen, J. A. R.; Catal. Today 2008, 130, 170.

30. Joshi, Y. V.; Ghosh, P.; Venkataraman, P. S.; Delgass, W. N.; Thomson, K. T.; J. Phys. Chem. C 2009, 113, 9698.

31. Aray, Y.; Rodriguez, J.; J. Mol. Catal. A:Chem. 2007, 265, 32.

32. Aray, Y.; Rodriguez, J.; Vidal, A. B.; Coll, S.; J. Mol. Catal. A: Chem. 2007, 271, 105.

33. Borges, I.; Silva, A. M.; Aguiar, A. P.; Borges, L. E. P.; Santos, J. C. A.; Dias, M. H. C.; J. Mol. Struct. THEOCHEM 2007, 822, 80.

34. Silva, A. M.; Borges, I.; J. Comput. Chem. 2011, 32, 2186.

35. Lee, C. T.; Yang, W. T.; Parr, R. G.; Phys. Rev. B: Condens. Matter Mater. Phys. 1988, 37, 785.

36. Hay, P. J.; Wadt, W. R.; J. Chem. Phys. 1985, 82, 299.

37. Frisch, M. J.; Trucks, G. W.; Schlegel, H. B.; Scuseria, G. E.; Robb, M. A.; Cheeseman, J. R.; Montgomery, J. A.; Vreven, T.; Kudin, K. N.; Burant, J. C.; Millam, J. M.; Iyengar, S. S.; Tomasi, J.; Barone, V.; Mennucci, B.; Cossi, B.; Scalmani, G.; Rega, N.; Petersson, G. A.; Nakatsuji, H.; Hada, M.; Ehara, M.; Toyota, K.; Fukuda, R.; Hasegawa, J.; Ishida, M.; Nakajima, T.; Honda, Y.; Kitao, O.; Nakai, H.; Klene, M.; Li, X.; Knox, J. E.; Hratchian, H. P.; Cross, J. B.; Adamo, C.; Jaramillo, J.; Gomperts, R.; Stratmann, R. E.; Yazyev, O.; Austin, A. J.; Cammi, R.; Pomelli, C.; Ochterski, J. W.; Ayala, P. Y.; Morokuma, K.; Voth, G. A.; Salvador, P.; Dannenberg, J. J.; Zakrzewski, J.; Dapprich, S.; Daniels, A. D.; Strain, M. C.; Farkas, O.; Malick, D. K.; Rabuck, A. D.; Raghavachari, K.; Foresman, J. B.; Ortiz, J. V.; Cui, Q.; Baboul, A. G.; Clifford, S.; Cioslowski, J.; Stefanov, B. B.; Liu, G.; Liashenko, A.; Piskorz, P.; Komaromi, I.; Martin, R. L.; Fox, D. J.; 
Keith, T. J.; Al-Laham, M. A.; Peng, C. Y.; Nanayakkara, A.; Challacombe, M.; Gill, P. M. W.; Johnson, B.; Chen, W.; Wong, M. W.; Gonzalez, C.; Pople, J. A.; Gaussian 03, Revision C.02 ed.; Gaussian, Inc.: Pittsburgh, PA, USA, 2003.

38. Jaguar, version 7.9, Schrödinger, LLC, New York, NY, 2012.

39. Pereira, M. S.; da Silva, A. M.; Nascimento, M. A. C.; J. Phys. Chem. C 2011, 115, 10104.

40. Orita, H.; Uchida, K.; Itoh, N.; J. Mol. Catal. A: Chem. 2003, 193, 197.

41. Stone, A. J.; J. Chem. Theory Comput. 2005, 1, 1128.

42. Cramer, C. J.; Essentials of Computational Chemistry: Theories and Models; John Wiley \& Sons: Chichester, UK, 2004.

43. Borges, I.; Int. J. Quantum Chem. 2008, 108, 2615.

44. Anders, G.; Borges, I.; J. Phys. Chem. A 2011, 115, 9055.

45. Rico, J. F.; Lopez, R.; Ema, I.; Ramirez, G.; J. Mol. Struct. THEOCHEM 2005, 727, 115.

46. Lopez, R.; Rico, J. F.; Ramirez, G.; Ema, I.; Zorrilla, D.; Comput. Phys. Commun. 2009, 180, 1654.

47. Moraes, T. F.; Borges, I.; Int. J. Quantum Chem. 2011, 111, 1444.

48. Stone, A. J.; Chem. Phys. Lett. 1981, 83, 233.

49. Stone, A. J.; Alderton, M.; Mol. Phys. 1985, 56, 1047.

50. Stone, A. J.; The Theory of Intermolecular Forces, vol. 32; Oxford University Press: Oxford, UK, 1997.
51. Price, S. L.; Stone, A. J.; Chem. Phys. Lett. 1983, 98, 419.

52. Price, S. L.; Chem. Phys. Lett. 1985, 114, 359.

53. Price, S. L.; J. Chem. Soc., Faraday Trans. 1996, 92, 2997.

54. Price, S. L.; Int. Rev. Phys. Chem. 2008, 27, 541.

55. Ma, X. L.; Schobert, H. H.; J. Mol. Catal. A: Chem. 2000, 160, 409.

56. Bouwens, S.; Vanveen, J. A. R.; Koningsberger, D. C.; Debeer, V. H. J.; Prins, R.; J. Phys. Chem. 1991, 95, 123.

57. Leliveld, B. R. G.; van Dillen, J. A. J.; Geus, J. W.; Koningsberger, D. C.; de Boer, M.; J. Phys. Chem. B 1997, 101, 11160.

58. Sacks, L. J.; J. Chem. Educ. 1986, 63, 288.

59. Sacks, L. J.; J. Chem. Educ. 1986, 63, 373.

60. Atkins, P. W.; Physical Chemistry; Oxford University Press: Oxford, UK, 1998.

61. Huheey, J. E.; Keiter, E. A.; Keiter, R. L.; Inorganic Chemistry: Principles of Structure and Reactivity; Harper Collins College Publishers New York: New York, USA, 1993.

62. Wiegand, B. C.; Friend, C. M.; Chem. Rev. 1992, 92, 491.

Submitted: April 19, 2012

Published online: September 28, 2012 